\title{
SIGNIFICAÇÕES DOS DOCENTES SOBRE A EDUCAÇÃO INFANTIL: VIAJANDO ATRAVÉS DOS CONTOS DE FADA
}

Antonio Cavalcante Filho Ana Ignez Belém Lima ${ }^{(*)}$

Buscamos, neste artigo, discutir a compreensão da relação entre as imagens construídas pelos professores sobre a docência na educação infantil e sua forma de ser professor (subjetividade), a partir da identificação desses profissionais com o rico universo simbólico e mítico dos contos de fada. O estudo está fundamentado em uma pesquisa que foi efetivada com docentes pertencentes à rede pública municipal de ensino da cidade de Fortaleza.

Entendemos que os professores que atuam na educação infantil, como em outros níveis de ensino, passam valores, idéias, conceitos e imagens do mundo para as crianças aprendizes. Nenhuma educação pode se considerar neutra. Isso implica entender que a literatura e os materiais pedagógicos utilizados nas escolas, como por exemplo, os contos de fada, são elementos relevantes e necessários na e para a formação dos professores de educação infantil. Afinal, a seleção dos contos, a forma de trabalhá-los, a interpretação que deles se faz, a ênfase em certos elementos da história são aspectos que dizem respeito à subjetividade do professor e sua forma de expressar-se como tal. Nenhum desses aspectos é escolhido com critérios "puros", ou podem ser dissociados dos aspectos subjetivos do sujeito docente. Por conseguinte, devem ser levados em consideração nas formações, de forma que o professor possa ter a possibilidade de tomar consciência de suas escolhas e das implicações dessas no processo educacional.

Para dar conta dessa discussão e dos elos entre as significações sobre a docência na educação infantil e a forma como se expressam enquanto professores, considerando suas identificações com o simbolismo presente nos contos de fada, buscamos os aportes teóricos de Jung, que considera a psique como em permanente movimento totalizador e também integrador, vinculada à totalidade da vida nas suas esferas consciente e inconsciente (GASPARELLO, 2006).

A compreensão do papel da subjetividade como elemento constitutivo na formação e prática docente adquire importância à medida que se tenta captar a construção dos sentidos permeados na prática laboral dos professores e, num nível mais aprofundado, a significação das constelações simbólicas esboçadas por eles. Importante sempre anotar que essa subjetividade se constrói na

\footnotetext{
${ }^{(*)}$ Antonio Cavalcante Filho. Doutor em Educação, professor do curso de Pedagogia da Faculdade das Américas (FADAM); Supervisor Escolar da Prefeitura Municipal de Fortaleza. E-mail:cavalcantefilho1945@ yahoo.com.
} 
interface entre o social e o individual na medida em que as duas se configuram permanentemente. (REY, 2016).

O modo como o professor entende a educação infantil, as escolhas que ele faz para trabalhar com os alunos, as representações que ele constrói sobre o ensino e a aprendizagem, são aspectos que devem ser compreendidos, analisados e colocados em discussão com os próprios docentes. Esses elementos têm incidência direta na qualidade da educação. São elementos que vão compondo as mediações do conhecimento realizadas pelos professores, junto aos alunos.

É preciso ressaltar ainda que essas concepções dos professores sobre a educação infantil, vão se traduzindo na forma como interagem com as crianças, na ideia de avaliação, na seleção de conteúdos e na própria importância dada a esse nível de ensino. Contudo, essas concepções não nos chegam diretamente e nem sempre aparecem de forma clara e objetiva nos discursos dos professores. Uma das possibilidades ricas e significativas de captar essas concepções de um modo mais amplo e interligado ao próprio fazer docente é por meio do trabalho com os contos infantis. Afinal, eles traduzem simbolicamente elementos de muitas épocas e culturas.

Referenciado no objetivo acima identificado, viajaremos agora pelo reino encantado dos contos de fada e de seu simbolismo significante como recurso para tentar entender aspectos da constituição da subjetividade do professor, e com isso, suas interpretações dos contos e as relações simbólicas estabelecidas com a docência.

\section{A SUBJETIVIDADE E SUAS TESSITURAS PARA COMPREENDER A DOCÊNCIA}

A subjetividade vem sendo muito debatida atualmente. Sua emergência está, por um ângulo, associada às condições que possibilitaram o desenvolvimento das ciências humanas e sociais e, por outro, a percepção de que nas diversas situações desenvolvidas pelo existir humano na sociedade contemporânea (a condição de ser docente representa uma dessas situações), o entendimento da subjetividade pode proporcionar aportes compreensivos relevantes.

$\mathrm{Na}$ tessitura contemporânea, a consideração da subjetividade surge como tentativa de compreender o ser humano na sua complexidade do ser e do existir. É preciso entender as singularidades subjetivas na busca de continuar compreendendo as transformações sociais atuais, mas abrindo espaço para que o sujeito possa ser elemento ativo nesses processos transformativos.

Nessa perspectiva, a subjetividade é entendida, neste trabalho, como um sistema complexo e processual, contendo elementos da interface entre o social e o individual, carregado de sentidos e 
significados e que remete à relação constante entre o consciente e o inconsciente pessoal e coletivo. Essa subjetividade está estruturada por configurações que se intercambiam constantemente e sujeitas a um desenvolvimento permanente. (MOLON, 2011).

Os professores têm sido considerados fundamentalmente na sua dimensão intelectual, detentores de informações, sujeitos essencialmente reflexivos e com um "dever ser" de racionalidade manifesta. Essa percepção desconsidera os professores como seres possuidores de subjetividades e nuances identitárias que perpassam suas vidas tanto pessoais como suas atividades profissionais.

Os docentes são sujeitos que ao longo de suas experiências de ensino e aprendizagem explicitam sentidos integrando-os em seus condicionantes sociais na sua tessitura afetiva e emocional. (SCOZ, 2011). Não podemos olvidar, portanto, que essa prática social docente se dá em determinados contextos (RAYO, 2013) integrando-os nas suas dimensões emocionais numa relação dialetizadora e não justaposta.

A construção do conhecimento, as formas de aprendizagem e de ensino embora sejam eixos considerados objetivos, se constituem em processos que estão implicados com as estruturas subjetivas, na medida em que a própria história da humanidade é elaborada "por sujeitos que, ao construí-la, também se constroem no processo histórico”. (SCOZ; RODRIGUES, 2015, p. 80).

Dessa forma, a aprendizagem e o ensino não são dimensões que se situam externamente em relação aos professores, mas são momentos formadores essenciais que se definem através do sentido que essa aprendizagem e ensino possuem para eles, e que estão inseridos em seus históricos de vida. (SCOZ, 2011)

Necessário lembrarmos que as vivencias emocionais que integram os sentidos subjetivos são, em muitas situações, formações inconscientes (XAVIER; NUNES; SANTOS, 2008). Ora, trabalhar com o inconsciente na subjetividade dos professores não é adentrar no caminho da irracionalidade. É aceitarmos que essa dimensão é importante no constituir-se docente, é avançarmos que o processo educativo é o locus de transformação, de possibilidade de expansão da consciência em direção aos elementos situados no inconsciente e no campo do desconhecido (GASPARELLO, 2006).

Importante assinalar que hoje não se questiona mais a existência ou não do inconsciente. Atualmente existem tecnologias que revolucionaram o entendimento sobre o inconsciente, "essas tecnologias tornaram possível pela primeira vez na história da humanidade, uma verdadeira ciência do inconsciente”. (MLODINOW, 2013, p. 9). 
No presente estudo optamos por trabalhar com o conceito de inconsciente junguiano. Para Jung (2011) o conceito de inconsciente abarca, além dos conteúdos reprimidos, todo o material psíquico subliminar que se encontra no limiar da consciência, incluindo também as próprias percepções subliminares dos nossos sentidos, e um vasto material que não alcança o nível da consciência.

Segundo Jung (1986) o inconsciente é um espaço em permanente movimento, que coordena esse movimento com a consciência e que contém um grande material psíquico que vai além dos conteúdos infantis reprimidos, sob influência do ambiente moral prevalente.

A partir dessas reflexões Jung avança se fundamentando em fatos empiricamente recolhidos em suas observações analíticas para um conceito novo, e controverso, o de que o inconsciente contém, além do material vivencial de cada ser humano, componentes de ordem impessoal, elementos de ordem coletiva, que o levou à formulação do inconsciente coletivo. "The collective unconscious is composed of a culturally universal unity at its core with an infinite number of culturally universal archetypes surrounding the core" (SMITH; VETTER, 1991, p. 99). Dessa forma esse inconsciente coletivo contem materiais universais, impessoais, coletivos, sob a construção de categorias que são herdadas, denominadas arquétipos. Esses elementos arquetípicos estão presentes em várias culturas como destaca Adamski (2011, p. 564): “Themes of archetypal images are the same for all cultures, are common to all people of different ages, races, and cultures and correspond to the phylogenetically conditioned part of the human structure". Especificamente os arquétipos se caracterizam "por la tendencia innata, que no aprendida, a experimentar las cosas de cierta forma y no de outra". (MORENO; HUGHES, 2016, p. 2).

Jung usou vários caminhos e diferentes recursos para acessar a compreensão da psique humana. Procedimentos que passaram pela religião, alquimia, mitologia, sonhos, filosofia, literatura e as artes de uma forma mais ampla (SANTOS, 2008) e que não se limitaram apenas a leituras, mas que foram concretizados em momentos empíricos, “[...] due to this fact, Jung travelled abroad, in order to explore the life of primitive peoples, and to be in direct contact with them" (ADAMSKI, 2011, p. 565).

Desse modo, é no interior desse constructo teórico junguiano que os contos de fada e seu rico material simbólico se inscrevem como um portal de acesso ao inconsciente coletivo. Os contos de fada são, num só tempo, nossa entrada e nosso guia nesse universo. Eles representam o caminhar pelo solo inconsciente, enquanto seu traduzir se encontra na globalidade dos vários temas que conecta o desenrolar do fio condutor da história. (FRANZ, 2008). 
Outras perspectivas teóricas que também trabalham o inconsciente corroboram com a visão de Franz, como Bettelheim (1980, p. 14) quando afirma:

[...] aplicando o modelo psicanalítico da personalidade humana, os contos de fadas transmitem importantes mensagens a mente consciente, a pré-consciente e a inconsciente, em qualquer nível que esteja funcionando no momento. Lidando com problemas humanos universais, particularmente os que preocupam o pensamento da criança, estas estórias falam ao ego em germinação e encorajam seu desenvolvimento, enquanto ao mesmo tempo aliviam pressões pré-conscientes e inconscientes.

Por isso, os contos de fada e os contos em geral, representam canais de compreensão da psique humana coletiva trazendo, também, elementos simbólicos e representativos que envolvem diversas questões cotidianas. (XAVIER FILHA, 2011). Eles permitem, também, “[...] un acercamiento a las diferentes fases presentes en el proceso de individuación donde el sujeto llega a ser un individuo, entendiendo por individualidad - parafraseando a Jung - nuestra intimísima, definitiva e irrepetible manera de ser”. (TAMAYO, 2013, p. 465). Eles possuem, ainda, como que um tênue fio que perpassa em ambientes culturais diferentes encobertos por nomes e personagens vinculados à história desses locus, mas que repetem uma temática, muitas vezes, similar.

Assim, nos contos populares do mundo inteiro, em todas as épocas, encontramos temas muitos semelhantes, como o da madrasta que maltrata a enteada (Cinderela, Vassalissa, Branca de Neve, Marama no Rio dos Jacarés, etc.), ou as peripécias de três irmãos cujo pai quer ver quem vence melhor as provas da vida, e faz com que saiam de casa e procurem um emprego. "O desenlace quase sempre mostra que o menos preparado, o caçulinha, o que pior montaria tem, o que mais bobo parece, é quem melhor se sai”. (BONAVENTURE, 2010, p. 22).

Hodiernamente os contos de fada são associados, quase que de forma automática, as histórias voltadas preferencialmente para crianças, sendo muito trabalhados nas atividades educativas desenvolvidas nas instituições dedicadas ao ensino infantil. Franz (2002, p. 2) nos remete a essa associação: “[...] O fato de que agora estejam relegados às crianças revela uma atitude típica - que eu diria define nossa civilização - segundo a qual o material arquetípico é encarado como algo infantil".

\section{O PERCURSO NA COMPREENSÃO DAS SIGNIFICAÇÕES DOS DOCENTES}

A metodologia utilizada nesse estudo deu ênfase na abordagem qualitativa por considerá-la mais adequada ao objeto de pesquisa em estudo e, especificamente, por possibilitar a captação de “aspectos indirectos que llevaran a interpretaciones no evidentes en la expresión intencional de los 
individuos estudiados" (REY, 2017, p. 121). Sempre necessário se faz alertar que "el curso de una investigación cualitativa constructivo-interpretativa es un proceso hipotético que puede ser negado por la emergencia de nuevos indicadores que refuten el camino dominante de la construcción teórica hasta ese momento". (REY; MARTÍNEZ, 2016, p. 10). Assim, os processos aqui investigados são sistemas abertos a outras investigações científicas. O método de investigação escolhido para atingir os objetivos propostos foi o estudo de caso único por considerá-lo um instrumento capaz de captar com intensidade a problemática a ser investigada dentro de um marco geográfico e temporal.

O campo pesquisado foi uma das unidades escolares pertencente ao sistema municipal público de ensino da cidade de Fortaleza. A seleção da escola obedeceu ao critério de apresentar em seu Projeto Político Pedagógico propostas direcionadas à utilização, como instrumento didático, dos contos de fada; estrutura física (materiais e recursos) que favoreçam essa proposta e professores que usam os contos no seu dia a dia na sala de aula.

Os sujeitos investigados foram duas professoras da escola (uma do Infantil IV e uma do Infantil V) que se enquadraram nos critérios assim especificados: aceitaram participar dessa pesquisa; estar atuando nas salas de Infantil IV e V (faixa etária de quatro a cinco anos); ser graduados (as) em Pedagogia; possuir, no mínimo, três anos de experiência na educação infantil e ter participado de, pelo menos, um curso de formação continuada na área referida.

Utilizamos como procedimentos para coleta de dados a aplicação de um roteiro para análise simbólica do conto de fada. Para a construção do roteiro para análise simbólico tomamos como referência os aportes de Franz (2008).

O ambiente foi estruturado numa sala, a mais tranquila possível, com música ao fundo, ficando as docentes e o pesquisador sentados no chão da sala. Nesse momento, as docentes iniciaram a contação da história escolhida, seguido da aplicação do roteiro para análise simbólica do conto exposto. Este roteiro se constitui da solicitação às entrevistadas que expressassem através de desenhos ou pinturas a primeira imagem que elas tiveram após a contação da história e de indagações sobre a compreensão que as docentes obtiveram sobre a história contada.

$\mathrm{Na}$ análise e interpretação dos dados, foram considerados os objetivos da investigação, seus limites e um sistema de referências para avaliar quais dados serão úteis ou não. Sendo assim buscamos identificar as classificações e categorias de análise que possibilitaram uma reflexão sobre os dados coletados. Desta forma identificamos as seguintes categorias: significação do conto e relação do conto com a docência. 


\section{AS PROFESSORAS E SUAS PERCEPÇÕES NA MEDIAÇÃO COM OS CONTOS DE FADA}

A análise dos dados foi efetivada a partir das transcrições das gravações realizadas com as professoras investigadas. Este procedimento nos permitiu captar, com maior discernimento, em muitos momentos, nuances que não foram imediatamente percebidas pelo pesquisador.

A utilização do roteiro simbólico como instrumento de pesquisa buscou captar conteúdos que escapam à nossa percepção consciente e também tentar ir um pouco além das nossas próprias referencias pessoais. Esse instrumento de pesquisa, elaborado pelo pesquisador, constou de desenhos ou pinturas que foram solicitados às professoras pesquisadas, referentes às imagens que elas tiveram logo depois da exposição do conto escolhido e também de perguntas que buscaram abarcar a compreensão que as docentes obtiveram sobre a história narrada.

Os contos escolhidos e lido pelas professoras foram: João e Maria e Chapeuzinho Vermelho. A seguir identificaremos o que os dados obtidos revelaram.

\section{As percepções do conto João e a Maria (Professora 1)}

A história de "João e Maria" principia colocando a questão da pobreza e da privação, das dificuldades de criar os filhos num contexto de fome. Pode parecer apenas um conto realístico do ponto de vista sociológico. Mas não é só isso. Sigamos a compreensão da professora.

Ela situa o conto em dois ambientes: na família (casa) e na floresta. A professora percebe que o ambiente floresta é o espaço onde passam a acontecer o maior número das ações, "então ela passa a acontecer na floresta”. (PROFESSORA 1). O conto se desenvolve em grande parte na floresta e os acontecimentos envolvem mais diretamente as personagens protagonistas da história, João e Maria, que também são, para a professora, as personagens mais interessantes.

Notemos que as personagens mais interessantes são referidos como os principais, João e Maria. A docente não sente falta de nenhum personagem, mas poderíamos perguntar: e a mãe dessas crianças? Talvez tenha morrido de parto, fato comum em determinada época da história. $\mathrm{O}$ fato é que as crianças têm uma madrasta. E a madrasta representa aspectos negativos. Todos sabem que quando se fala esse termo as pessoas logo associam a possíveis maus tratos, dificuldades no relacionamento com os filhos que não foram gerados por ela, mas por outra mulher. Há um simbolismo presente que a madrasta é algo ruim, diferente da mãe que é algo considerado intrinsecamente bom. 
Quando indagada sobre contradições e conflitos na história, a professora detecta três: A rejeição da madrasta, a falta de firmeza do pai e o momento em que as crianças pegam as joias da bruxa. Sobre a interpretação geral do conto ela o associa a questão da família. Mas a família dos alunos, "a questão deles ficarem sozinhos, muitos dizem: olha eu fico sozinho na minha casa. Não aceitar nada de estranho." (PROFESSORA 1).

Com relação ao vínculo do conto com a docência, a professora enfatiza a ligação com a questão familiar e considera que a interpretação das crianças, que ela denomina de reação, depende muito da professora. Ela assim se posiciona: "eu percebo que na contação de história a reação que as crianças dão é muito de acordo com a forma como você conta se você vai colocando vida na história a maneira como você fala”. (PROFESSORA 1).

Notamos, então, que a professora não tira conclusões sobre a história que possam se situar no terreno do simbolismo presente nos contos de fada. Ela expressa quase que aquilo que é percebido de forma mais imediata, que tem relação com os aspectos do conto, que estão mais explícitos, não com seus significados não revelados.

Seu entendimento do conto se situa, preferencialmente, no núcleo mais evidente da história: a de uma família e seus problemas. Mesmo suas conclusões mais verticalizadas como, por exemplo, a falta de firmeza do pai, rejeição da madrasta, apanhar objetos que não são seus, identificação das crianças com suas vivencias familiares, são elementos que estão mais claros, mais evidenciados.

A professora não captou que o conto pode transmitir para as crianças mensagens não conscientes e que elas são capazes de entender, de captar. Entender o simbolismo presente nos contos pode não ser uma tarefa fácil. Assim, a madrasta pode representar aspectos que também podem ser encontrados, pelos filhos, nas mães. Ao crescerem os filhos necessitam se separarem da mãe para seu próprio amadurecimento. O que sente um filho quando após anos sendo alimentado e aconchegado pela mãe, ela resolve que agora tem de se alimentar sozinho? Ou quando é deixado na escola, no meio de gente estranha, de pessoas que não fazem parte de sua convivência familiar?

Toda mãe talvez seja um pouco madrasta. Talvez mãe e madrasta sejam polos de um mesmo todo, façam parte de uma mesma pessoa, simbolizem aspectos opostos de uma mesma pessoa.

Por outro lado a atitude de certa passividade do pai que mesmo sofrendo, termina por concordar com os planos da mulher, pode demonstrar que todo e qualquer homem tem seus momentos de fragilidade, que o elemento masculino, culturalmente identificado com a ação, força, possui seu animus, sua contra parte feminina. E aqui as determinações culturais são evidentes. A 
forma como os arquétipos se manifestam guarda relação com a cultura, com seu corte diacrônico. Não nos esqueçamos que os arquétipos são fôrmas sem conteúdo determinados a priori.

A professora fala da floresta, mas não percebe que a floresta é o campo das vivencias existenciais das crianças, suas dificuldades necessárias ao seu crescimento, seu amadurecimento, o que concorre para o final feliz da história. A bruxa, que atrai as crianças para sua casa, também pode representar o lado escuro de toda mãe, além de significar

[...] nossa 'floresta interior', escondida em algum lugar de nossa psique. Não basta se desgarrar, cortar o cordão umbilical que nos segura perto de nossa mãe pessoal, há ainda dentro de nós outra 'mãe' bem ambígua, positiva e negativa ao mesmo tempo, que temos de enfrentar. (BONAVENTURE, 2010, p. 119).

Não esqueçamos que a bruxa, no conto, cuida, trata bem as crianças em um determinado momento, mas tenta destruí-las em outro. "Resta saber onde é que encontramos essa figura, tanto fora como dentro de nós" (BONAVENTURE, 2010. p.119).

Quando a professora responde, interrogada sobre a relação da história com a docência na educação infantil, ela afirma "que a professora tem que pensar: o que essa história vai oferecer aos meus alunos, que a professora tem que ter a sua vivencia da história" e conclui "a questão família mesmo que eu acho”. (PROFESSORA 1). Diz-nos que contar histórias na educação infantil tem ligação com exemplos, modelos, que os contos podem apresentar. Também que o professor (categoria genérica), é elemento importante nesse contar, através da sua vivencia, de seu experienciar, o que, de certa forma, é coerente com sua conclusão que "João e Maria" é um conto que remete às questões familiares de seus alunos, essencialmente. Mas por que não dela também? Afinal, suas vivencias são dados que devem ser levados em consideração, segundo sua própria resposta.

Além do mais será que a interpretação e relações estabelecidas, pela professora, com as questões familiares não nos remete a uma identificação da docência na educação infantil, com a família, com a mulher, com o cuidar, permanecendo os aportes profissionais secundarizados? Educação infantil, para ela, talvez tenha elos com características mais familiares, mais afetivas, mais da mulher e seus filhos. Aspectos que a formação poderia problematizar e levantar interessantes reflexões.

\section{As percepç̃̃es do conto Chapeuzinho Vermelho (Professora 2)}

A segunda professora, sujeito dessa pesquisa, principia suas respostas no roteiro simbólico, afirmando que a história acontece "há muito tempo atrás" e a situa em uma "pequena vila próxima 
a uma floresta". Sobre a falta de algum personagem responde que sim e observa a ausência do pai de Chapeuzinho Vermelho. Quanto aos conflitos, contradições ou ambiguidades presentes na história, ela também afirma que sim e os coloca como oposições entre o que é certo e errado, verdade e mentira, obedecer e desobedecer.

Sua resposta sobre a interpretação do conto não foi realmente um entendimento sobre ele, mas um resumo da história, o que fica evidenciado que a professora 2 não respondeu ao que se propôs na indagação, que foi tentar alcançar sua interpretação da história, com todas as suas nuances subjetivas. Sua resposta sobre a relação da história com o contexto da docência na educação infantil abordou aspectos relativos ao ensino das professoras, sobre regras gerais de convivência, certo e errado, respeito, consequências negativas advindas de atos errados na percepção da professora.

Antes de tentar analisarmos as respostas dadas pela professora 2, gostaríamos de observar que a história escolhida por ela tem uma (dentre outras), versão totalmente diferente do final feliz contado nesse conto. É a elaborada por Charles Perrault (1628-1703) onde o lobo come a vovó e o Chapeuzinho Vermelho, tentando indicar os perigos, para as jovens, de conversar com estranhos.

Situar a história em um tempo não determinado é o começo clássico da maioria dos contos de fada, porque o tempo como é entendido e vivido nessa nossa existência dimensional, não é relevante nas histórias dos contos, porque eles trabalham com elementos que se situam além ou fora do tempo e espaço que nós conhecemos, no campo do inconsciente coletivo. "Em contos de fada o tempo e o lugar são sempre evidentes porque eles começam com 'Era uma vez' ou algo semelhante, que significa fora de tempo e de espaço - a 'terra-de-ninguém' do inconsciente coletivo.” (FRANZ, 2008, p. 48). A professora apenas reafirma o que está escrito no conto e, como sua colega, não faz inferências sobre isso. Já ressaltamos as dificuldades de entender as mensagens, sob a forma de símbolos, contida nos contos de fada e a professora apenas confirma, com sua resposta, o que dissemos nas outras análises.

Lamentavelmente a professora não nos forneceu seu entendimento do conto, sua forma de interpretá-lo, mas apenas uma síntese da história que contou. Isso pode nos alertar sobre o que ela entende sobre interpretar uma história. A pergunta do roteiro foi clara e tanto é assim que a sua colega não mostrou dificuldade de entendimento e foi capaz de dar suas respectivas "versões" subjetivas das histórias escolhidas. Mas, a professora não o fez. Parece que ela confundiu interpretar uma história e contar o que essa história narrou. Também pode ser que ela tenha tido alguma dificuldade em captar o todo do conto, em dar coerência a esse todo numa interpretação geral da 
história narrada por ela. Optou, então, pelo mais fácil que foi reproduzir sinteticamente a trama de uma forma literal.

A sua escolha dos personagens mais interessantes, Chapeuzinho e o Lobo, pode nos ter revelado identificações com aspectos opostos da psique. Chapeuzinho é associado a elementos como bondade, ingenuidade, enquanto o Lobo carrega uma representação de características negativas. Os dois personagens, embora se contraponham no conto, simbolizam polaridades que fazem parte de um mesmo todo, energias que podem fluir por vários caminhos, buscando, nessas mudanças de fluxos, manter certo tipo de equilíbrio na psique.

A professora também é lobo, também tenta seduzir, levar por atalhos perigosos, destruir simbolicamente a ingenuidade, usar de estratégias para "comer" a Chapeuzinho. A identificação com figuras carregadas de caracteres negativos pode se dar tanto dentro como fora de nós. Talvez a professora seja um pouco "lobo" na sala de aula, ao lidar com questões difíceis, com situações em que sua paciência é posta à prova, em que sua persona de professora ameace se desestabilizar por alguns momentos. Mas é muito mais difícil reconhecer essas características dentro dela mesma. E muito mais complexo ainda admitir que o "lobo" possa lhe atrair, como pode exercer essa atração sobre qualquer um de nós. "Passa a ser, em relação a si mesma (e aos outros), alguém que destrói o que há de mais puro, simples, ingênuo, infantil” (BONAVENTURE, 2010, p. 119).

Sendo assim, a professora possui na sua persona de docente elementos negativos que estão radicados na sua subjetividade de maneira não intencional, não consciente. Nos sentidos construídos por ela ao longo do seu percurso profissional, também se acham conectados dados do seu inconsciente que compõe sua subjetividade e que, digamos nós, não passariam pelo crivo da aceitação social. Isso pouco importa para o inconsciente. Além do mais não nos esqueçamos que “[...] consciência/inconsciência não formam uma dicotomia, mas dois momentos diferentes da experiência subjetiva que se constituem dentro de uma nova unidade, que são os sentidos subjetivos."(SCOZ, 2011, p. 39). E esses sentidos subjetivos que são influenciados pelo inconsciente, também o são de forma dinâmica já que "o inconsciente jamais se acha em repouso, no sentido de permanecer inativo, mas está sempre empenhado em agrupar e reagrupar seus conteúdos" (JUNG, 2011, p.16).

Com relação ao vinculo entre a história escolhida e o contexto do ensino na educação infantil, a professora coloca responsabilidades que as docentes devem ter de ensinar às crianças o que elas devem fazer. Ela encontra no conto de Chapeuzinho Vermelho oportunidades de extrair lições a ser dadas às crianças. Relaciona a história com contextos concretos da sua experiência 
como professora, buscando ensinamentos que possam ser esclarecidos às crianças e que se complementam com os que elas trazem da família, ela assim se coloca:

A relação que eu faço com a nossa prática docente tá nesse sentido que cabe a nós professores ta instruindo as crianças em muitas coisas que cabe pra família também, mas que acaba caindo pra nós professores tanto instruindo as crianças com relação a seus direitos, a seus deveres, o que elas devem fazer, o que elas não podem, o que é certo, o que é errado. (PROFESSORA 2).

A função docente tem aqui um trabalho de passar valores, estabelecer o "dever ser" às crianças, de certo modo, complementar a educação familiar apontando caminhos. Notamos também aqui como em outras análises anteriores, um não entendimento do rico simbolismo presente nos contos de fada. "A partir de símbolos apropriados, que de maneira diversa alcançam o consciente, o elemento estrutural arquetípico, que faz parte desse processo e é carregado de energia, faz-se perceptível” (ROTH, 2011, p.181).

A professora não tem percepção desse elemento arquetípico básico que se manifesta nos símbolos dos contos de fada. Suas relações não vão além do "horizonte" valorativo, da extração de algumas nuances comportamentais que devem ser explicadas às crianças. A inexistência do elemento masculino no inicio do conto e a presença dominante do feminino, por exemplo, apenas foi sentida pela professora quando ela diz faltar o pai de Chapeuzinho. Essa falta do masculino é compensada pela sua presença, inconsciente, na psique. A atividade do inconsciente possui uma relação compensatória com a consciência. "Só em casos patológicos tal atividade pode tornar-se autônoma; de um modo normal ela é coordenada com a consciência, numa relação compensadora" (JUNG, 2011, p. 16).

Outro elemento que pode ser destacado no conto é o capuz ou chapéu usado pela protagonista da história. Ele pode representar o poder, a soberania, como em muitos contextos culturais diferentes. O Lobo pode representar atributos pessoais e que estão sendo projetados no outro, deixando a esse outro as possibilidades daí advindas.

"Chapeuzinho Vermelho" nos fala dos sentimentos humanos, de nossas paixões, medos e agressividades projetadas. Podemos inferir que Chapeuzinho se torna mais madura ao enfrentar os perigos do exterior, mas principalmente, quando se depara com aqueles que estão dentro dela mesmo.

A professora não nos diz dessa riqueza simbólica, mas na sua manifestação de certa identificação com o Lobo nos comunicou que o lado escuro de sua natureza está presente, está 
atuando, mesmo sem seu reconhecimento ou adesão consciente, capaz de se atualizar quando circunstancias existenciais favorecerem seu surgimento. "Uma vez que a natureza humana não é constituída apenas de pura luz, mas de muita sombra, as revelações obtidas pela análise prática são às vezes penosas e tanto mais penosas (como é geralmente o caso) quanto mais se negligenciou, antes, o lado oposto" (JUNG, 2011, p. 29).

\section{CONSIDERAÇÕES FINAIS}

A partir do objetivo proposto para este artigo, compreender a relação entre as imagens que os professores tem acerca da docência e sua forma de ser professor na Educação infantil, observamos que as imagens elaboradas pelas professoras destacam, no plano cognitivo, exclusivamente aspectos positivos vinculados às docentes, atribuindo-lhes uma importância fundamental no processo ensino aprendizagem.

Com relação aos contos e a sua utilização como instrumento em sala de aula as professoras não foram capazes de identificar sua rica natureza simbólica. Elas apenas se ativeram aos conteúdos manifestos das histórias e estabeleceram elos com suas vidas concretas. Nota-se aqui certa rotinização no uso dos contos. É praticamente uma utilização por tradição, como se fosse algo obrigatório, uma cartilha da qual não se pudesse fugir. Faz-se assim porque sempre foi assim, é o mais adequado, o mais óbvio.

As docentes demonstraram não ter uma convicção mais verticalizada de saber por que tais contos devem ser trabalhados e o que eles implicam, através de seus significados simbólicos, para as crianças e seu processo educacional. Isso reflete uma lacuna nos processos formativos das professoras na medida em que aqueles não trabalham com a possibilidade pedagógica e a dimensão profundamente humana dos contos de fada, limitando as docentes no acesso ao rico e multi matizado universo infantil. A superação dessa lacuna nos processos formativos terminaria por implicar, ainda, num trabalho mais amplo do trabalhador docente sobre ele mesmo, afetando suas representações e práticas efetivas.

Entendemos que a pesquisa realizada nos leva a reafirmar a importância da subjetividade e a propor a partir dessa constatação, a inserção nos processos formativos das professoras de educação infantil, elementos que considerem essa subjetividade e busquem levar em conta os sentimentos negativos captados, assim como contribuir para que as docentes reconheçam o simbolismo presente nos contos de fada. Elementos também que ressaltem o papel da imaginação e da criatividade como aspectos centrais não só na educação infantil, mas também na formação docente. Afinal, quando 
falamos de simbolização não estamos defendendo que as professoras tenham de dominar uma linguagem ou conhecimento de âmbito mais psicológico; mas sim que possam ir além das interpretações rotineiras dos contos, dos olhares restritos ao senso comum; das análises, muitas vezes, preconceituosas ou pouco questionadas. Defendemos que possam usar os contos como um rico e potente material de expressão e expansão do ato criativo e de produção de novos sentidos sobre si e sobre o mundo por parte delas e das próprias crianças. 


\section{REFERÊNCIAS}

ADAMSKI, Adam. Archetypes and the Collective Unconscious of Carl G. Jung in the Light of Quantum Psychology. Neuroquantlogy, v. 9, p. 563-571, set. 2011.

BETTELHEIM, Bruno. A psicanálise dos contos de fada. 29 ed. Rio de Janeiro: Paz e Terra, 2014.

BONAVENTURE, Jette. Porque os contos populares falam a todos? In. SPACCAQUERCHE, Maria B. Encontros de psicologia analítica. São Paulo: Paulus, 2010.

FRANZ, Marie-Louise Von, A interpretação dos contos de fada. 7. ed. São Paulo: Paulus, 2008.

A sombra e o mal nos contos de fada. 3. ed. São Paulo: Paulus, 2002.

GASPARELLO, Vânia Medeiros. Subjetividade e formação de professores: algumas reflexões a partir da psicologia analítica. Revista E-Curriculum. São Paulo, v. 2, n. 3, dez. 2006.

GOMEZ, A.D; REY, F.G. CARDONA, A. M. A. Pensar el Método en los Processos de Investigación en Subjetividad. Revista Ces Psicologia, v. 10, n. 1, p. 129-145, 2017.

JUNG, Carl Gustav. O eu e o inconsciente. 22. ed. Petrópolis: Vozes, 2011.

A Dinâmica do Inconsciente. Rio de Janeiro: Vozes, 1986.

MACERA, Irene Marina. Um estúdio de las concepciones docentes acerca de la formación permanente. Educación y Educadores. v. 15, n. 3, p. 513-531, set./dec. 2012.

MLODINOW, Leonard. Subliminar. Como o inconsciente influencia nossas vidas. Rio de Janeiro: Zahar, 2013.

MOLON, Susana Inês. Notas sobre Constituição do Sujeito, Subjetividade e Linguagem. Psicologia em Estudo, v. 16, n. 4, p. 613-622, out./dez. 2011.

MORENO, M. G.; HUGHES E.C.H. Estudio de la Obra de Stevenson sobre la base de la teoria de Jung del Arquetipo de la Sombra en el extraño caso del Dr. Jekill y Mr. Hyde. Alpha, n. 42, jul. 2016.

RAYO, Orfa Garzón. Eje: Desde la didáctica In. Acerca de la subjetividade contemporânea: Evidencias y reflexiones. Cuadernos del centro de Estudios em Diseño y Comunicación. Buenos Aires, ensayos. n.43, mar, 2013.

REY, Gonzalez. La Epistemología Qualitativa y el Estudio de la Subjetividad en una Perspectiva Cultural- Histórica. Conversación con Fernando González Rey. Rev. Estud. Soc. n. 60, abril-junio, P. 120-127, 2017.

REY, F. G; MARTÍNEZ A. M. Una Epistemologia para el Estudio de la Subjetividad: Sus Implicaciones Metodológicas. Psicoperspectivas Individuo y Sociedad, v. 15, n.1, p. 5-16, 2016.

ROTH, Wolfgang. Introdução à Psicologia de C. G. Jung. Petrópolis: Vozes, 2011

SANTOS, Sandra Regina. Jung: um caminhar pela psicologia analítica. Rio de Janeiro: Wak Editora, 2008.

SCOZ, Beatriz Judith Lima. Identidade e subjetividade de professores: sentidos do aprender e do ensinar. Petrópolis: Vozes, 2011.

SCOZ, B. J. L; RODRIGUES, V. N. S. Aula de história: subjetividade e memória na aprendizagem de alunos. Revista Psicologia Escolar e educacional, v. 19, n.1, p.79-86, jan./abr. 2015.

SMITH, B.D; VETTER, H.J. Theories of personality. Englewood Cliffs. NJ: Prentice-Hall. 1991.

SILVA, Zélia M. Carvalho. História e memória da educação infantil em Teresina: Piauí 1968-1996. 2008. Dissertação (Mestrado em Educação) Universidade Federal do Piauí, Teresina, PI, 2008.

TAMAYO, A. P. Interpretación Hermenéutica de los Cuentos: Ikú el Pájaro de Oro y Zarevich Iván, El Pájaro de Fuego e el Lobo. Escritos, v. 21, n. 47, p. 463-490, jul./dic. 2013.

XAVIER, Alessandra; NUNES, Ana Ignéz B. L; SANTOS, Michelle S. dos. Subjetividade e sofrimentos psíquico na formação do sujeito na universidade. Revista Mal Estar e Subjetividade, v.8, n. 2, junho, Fortaleza, 2008.

XAVIER FILHA, Constantina. Era uma vez uma princesa e um príncipe... representações de gênero nas narrativas de crianças. Revista Estudos Feministas. Florianópolis, vol. 19, n. 2, p. 591-603, Maio/Ago. 2011. 


\section{RESUMO}

Este artigo busca compreender aspectos da significação dos professores sobre a educação infantil e elementos da sua subjetividade docente a partir do simbolismo dos contos de fada. Discute a relação entre as imagens dos professores sobre a docência e sua forma de ser professor na educação infantil. A pesquisa foi efetivada com docentes do Infantil IV e $\mathrm{V}$ pertencentes à rede pública de Fortaleza. Utilizou o estudo de caso como método de pesquisa e para a coleta de dados foi aplicado um roteiro para análise simbólica dos contos de fada. Conclui que as professoras investigadas não foram capazes de identificar a natureza simbólica dos contos.

Palavras-chave: contos de fada; subjetividade docente; educação infantil.

\section{SIGNIFICACIONES DE LOS DOCENTES SOBRE LA EDUCACIÓN INFANTIL: VIAJANDO A TRAVÉS DE LOS CUENTOS DE HADA}

\section{RESUMEN}

Este artículo busca comprender aspectos de la significación de los profesores sobre la educación infantil y elementos de su subjetividad docente a partir del simbolismo de los cuentos de hada. Discute la relación entre las imágenes de los profesores sobre la docencia y su forma de ser profesor en la educación infantil. La investigación fue efectuada con docentes del Infantil IV y V pertenecientes a la red pública de Fortaleza. Utilizó el estudio de caso como método de investigación y para la recolección de datos se aplicó un guión para el análisis simbólico del cuento de hada. Concluye que las profesoras investigadas no fueron capaces de identificar la naturaleza simbólica de los cuentos.

Palabras clave: cuentos de hada; subjetividad docente; educación Infantil.

\section{MEANINGS OF TEACHERS ON CHILDREN'S EDUCATION: TRAVELING THROUGH FAIRY TALES}

\section{ABSTRACT}

This article tries to understand aspects of the teachers' signification about the education of children and elements of their teaching subjectivity from the symbolism of fairy tales. It discusses the relationship between the images of teachers about teaching and their way of being a teacher in early childhood education. The research was carried out with teachers of Children IV and V belonging to the public network of Fortaleza. She used the case study as a research method and a script for the symbolic analysis of the fairy tale was applied to the data collection. It concludes that the investigated teachers were not able to identify the symbolic nature of the stories.

Keywords: fairy tales; teachers' subjectivity; childhood education. 